\title{
Removal and tracing of cephalosporins in industrial wastewater by SPE-HPLC: optimization of adsorption kinetics on mesoporous silica nanoparticles
}

\author{
Heba T. Elbalkiny ${ }^{1 *}$, Ali M. Yehia ${ }^{2,3}$, Safa'a M. Riad ${ }^{1,2}$ and Yasser S. Elsaharty ${ }^{2}$
}

\begin{abstract}
Cephalosporins are $\beta$-lactam antibiotics which are considered the most widely used for humans and animals in many countries. Solid phase extraction was applied using Oasis HLB cartridges for tracing three cephalosporins (cefadroxil, cefprozil, and cefradine) in industrial wastewater samples. Sample extraction was followed by chromatographic analysis. The developed high-performance liquid chromatographic method was used for the determination of these selected cephalosporins. Separation was achieved on a Hypersil $\mathrm{C}_{18}$ column with an isocratic elution of acidified water (pH 2.5) to methanol to acetonitrile (82:12:6 per volume) at a flow rate of $1.5 \mathrm{~mL} \mathrm{~min}^{-1}$ and UV detection at $254 \mathrm{~nm}$. Moreover, the proposed extraction and analysis procedures were applied to study the ability of mesoporous silica nanoparticles to remove cephalosporin residues from water by adsorption technique. A factorial design was applied to investigate the effect of $\mathrm{pH}$, initial cephalosporins concentration, and adsorbent concentration on the adsorption process using removal percentage as a response. The prediction model fit well to experimental data based on statistical analysis. Adsorption kinetics and isotherm have been also studied, and the experimental results indicated that the adsorption process followed the pseudo-second-order kinetic model and Freundlich isotherm.
\end{abstract}

Keywords: Cephalosporin residues, Mesoporous silica nanoparticles, Adsorption kinetics, Pharmaceutical wastewater treatment, Experimental design and HPLC-UV

\section{Introduction}

Detection and studying the fate of different pharmaceutical compounds in various environmental areas, especially in aquatic ecosystems, become the main tasks of environmental chemistry (Stuer-Lauridsen et al. 2000; Zuccato et al. 2000). Their presence in the environment arises from numerous sources: pharmaceutical industry, hospital wastewater, discharging of expired drugs by households, and also excretion of residues of drugs and their metabolites by animals and humans (Dębska et al. 2004; Meijer and Wilting 1997). Among those pharmaceuticals, antibiotics were usually monitored in the aquatic environment (Petrović et al. 2014). The continuous exposure of bacteria to even low concentrations of those antibiotics may lead

\footnotetext{
* Correspondence: htarek@msa.eun.eg

${ }^{1}$ Analytical Chemistry Department, Faculty of Pharmacy, October University for Modern Sciences and Arts (MSA), 6th of October City 11787, Egypt Full list of author information is available at the end of the article
}

to a selective proliferation of resistant microorganisms (Wang et al. 2015), which is why tracing of antibiotics discharged from different sources has received recently big interest. Cephalosporins are $\beta$-lactam antibiotics, and they are considered the most widely used for humans and veterinary antibiotics in many countries, with usage nearly $55-70 \%$ of the total antibiotics used by a human (Harris et al. 2012; Kümmerer 2009). They act as potent antimicrobial agents. Moreover, the manufacturing of cephalosporins increases every year due to the growth of the worldwide market needs (Ferech et al. 2006; Goossens et al. 2005). Some researchers have inspected their presence in wastewater and natural aquatic environments (Hue et al. 2014; Quesada-Molina et al. 2013; Wang et al. 2011; Yu et al. 2016).

The insufficient management of industrial and agriculture wastewater leads to contaminated and chemically polluted water, according to the World Health Organization (WHO) report; more than a hundred million people in the whole 
world were collecting untreated surface water from different sources in the year 2015 (Organization WH 2017), which is explaining the importance of developing improved methodologies for pharmaceutical wastewater treatment as part of water management (Gadipelly et al. 2014; Gleick 2002). Various methods have been developed and used; the most important were reverse osmosis (Jane 2010), ion exchange (Tiravanti et al. 1997), electrolysis (Rajkumar and Palanivelu 2004), and adsorption (McKay 1981; Wang and Peng 2010). These water treatment technologies are either time- or cost-prohibitive; on the contrary, adsorption technique is considered a fast, inexpensive, and widely applicable one (Lehr and Keeley 2005). Adsorption-based technique has a great efficiency as it removes contaminants and biological pollutants whether soluble or insoluble. Several adsorbents have been used for water treatment like soils (Thiele 2000), carbon-based materials (Carabineiro et al. 2011; Carabineiro et al. 2012; Karanfil et al. 1999), and silica (Lorphensri et al. 2006). For instance, treatment of water containing cephalosporins has been reported by biochemical treatments (Duan 2009), ion exchange resin (cefotaxime) (Vasiliu et al. 2011), multi-walled carbon nanotubes (cephalexin and cefixime) (Jafari et al. 2011), Cd multi-walled carbon nanotube (cefotaxime, cefradine, and cefazolin) (Fakhri et al. 2016), and magnesium oxide nanoparticles (cephalexin and cefixime) (Fakhri and Adami 2014) and using alga-activated sludge (Guo and Chen 2015).

The aim of this research is to develop a chromatographic method to detect the presence of three selected cephalosporins (cefprozil, cefadroxil, and cefradine) in pharmaceutical wastewater and to apply a simple wastewater treatment method using mesoporous silica nanoparticles (MSN) as effective adsorbent. The two-level fractional experimental design was employed for adsorption process optimization to get the best results as there are many factors included in the study. Factorial design is one of the most applied kind of experimental design, as it can estimate both the main effects and interaction effects with least experimental trials, time, cost, and with the better response (De Lima et al. 2011; Geyikci and Büyükgüngör 2013; Montgomery 2017). The kinetics of adsorption of each drug and its isotherm were also studied.

\section{Experimental Equipment}

High-performance liquid chromatography (Agilent 1200 series, Germany) equipped with quaternary pump, microvacuum degasser, thermostatted column compartment, and a multiple wave length detector (MWD) was used. Sample injections were made through an Agilent 1200 series autosampler. Data collection and processing were performed using Agilent Chemstation software, version A.10.01. Hypersil $\mathrm{C}_{18}$ high-performance liquid chromatography (HPLC) column $(4.6 \mathrm{~mm} \times 150 \mathrm{~mm}, 5 \mu \mathrm{m})$ from
Thermo Fisher Scientific was used. Solid phase extraction (SPE) was performed on a vacElut vaccum manifold, using Oasis hydrophilic-lipophilic balance (HLB) cartridges (12 cc, $500 \mathrm{mg}, 60 \mu \mathrm{m}$ particle size).

\section{Reagents and materials}

Cefadroxil, cefprozil, cefradine, and cephalexin drugs were generously supplied from GlaxoSmithKline (GSK); methanol and acetonitrile (HPLC grade) and orthophosphoric acid were purchased from Sigma Aldrich; hydrochloric acid and sodium hydroxide were supplied by El-Nasr Pharmaceutical Chemicals Company; and mesoporous silica nanoparticles (MSN) were purchased from NanoTech, Egypt (Additional file 1: Figure S1).

\section{Standard solutions}

A concentration of $1 \mathrm{mg} \mathrm{mL}^{-1}$ for cefadroxil, cefprozil, cefradine, and cephalexin (internal standard) were prepared using methanol as a stock solution, and then freshly prepared working solutions were obtained by dilution of the prepared stock solutions with mobile phase to obtain a concentration of $500 \mu \mathrm{g} \mathrm{mL}^{-1}$. All solutions were stored in dark bottles at $4{ }^{\circ} \mathrm{C}$. Their purity was tested using official chromatographic methods (Pharmacopoeia 2013).

\section{Procedures Sample preparation}

According to the Environmental Protection Agency (EPA), the samples were collected from pharmaceutical industries effluents located in Giza city, in an amber bottle using Teflon lined caps and then stored in a dark area at $4{ }^{\circ} \mathrm{C}$ after their filtration (David Duncan and Walker 2007). Samples were treated with $1 \mathrm{~mL}$ of $5 \%$ $(w / v)$ aqueous ethylenediaminetetraacetic acid (EDTA) solution to chelate the metal residues and acidified with sulfuric acid to $\mathrm{pH} 3$, prior to their extraction and preconcentration by solid phase technique using Oasis HLB cartridges. The cartridges were pre-conditioned with 3 $\mathrm{ml}$ of methanol and $3 \mathrm{ml}$ pure water, and then the samples passed through the cartridge at a flow rate of approximately $5 \mathrm{ml} / \mathrm{min}$. Then, these cartridges were washed subsequently with $6 \mathrm{ml}$ water and liquid was drained off under vacuum for $60 \mathrm{~s}$. The cephalosporins were eluted with $6 \mathrm{ml}$ of methanol-water, $(1: 1 \mathrm{v} / \mathrm{v})$. The eluate was collected in a 10-ml polypropylene tube with a screw-cap and evaporated to dryness at $40{ }^{\circ} \mathrm{C}$ using a nitrogen stream. The residue was dissolved in $1 \mathrm{ml}$ of the mobile phase before injection in HPLC. The same extraction procedures were applied on spiked pure water samples with different concentration of each drug, and the recovery of each drug was calculated. Tests were carried out with three replications. 


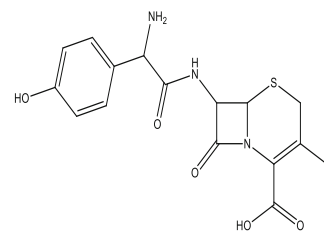

cefadroxil

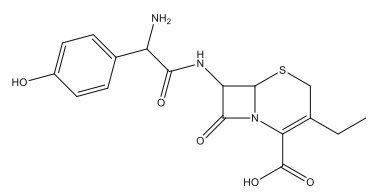

cefprozil

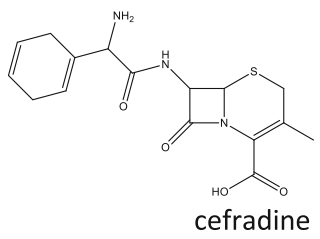

Fig. 1 Chemical structure of the three selected cephalosporins

\section{Optimization of chromatographic conditions}

Chromatographic method was developed using a $\mathrm{C}_{18}$ column with an isocratic elution of acidified water $(\mathrm{pH} 2.5)$ to methanol to acetonitrile $(82: 12: 6, v / v)$; the $\mathrm{pH}$ was adjusted using orthophosphoric acid, the flow rate was at $1.5 \mathrm{ml} / \mathrm{min}$, and the column temperature was maintained at $25^{\circ} \mathrm{C}$. The injection volume was $10 \mu \mathrm{L}$ and the ultraviolet (UV) detection was done at $254 \mathrm{~nm}$. System suitability parameters were calculated according to the United States Pharmacopeia (2009). Six standard solutions of each drug were prepared in the concentration range $10-200 \mu \mathrm{g} / \mathrm{ml}$ for cefadroxil, cefprozil, and cefradine by dilution of the working solution in amount of water followed by the addition of I.S, cephalexin (final concentration, $50 \mu \mathrm{g} / \mathrm{ml}$ ). The calibration curves of each were constructed by plotting the peak area ratio of analyte to that of I. S (cephalexin) against the corresponding concentration, from which the regression equations were calculated.

\section{Application for adsorption studies}

The developed chromatographic method was used to monitor the decrease in cephalosporins concentrations over time upon dispersing different concentrations of MSN in standard solutions of each drug that were prepared in phosphate buffer. The efficiency of MSN in adsorption of cephalosporins were studied, at different parameters: $\mathrm{pH}(\mathrm{A})$, the drug initial concentration (B), and the adsorbent loading dose $(\mathrm{C})$; a two-level factorial design $2^{3-1}$ was used to analyze the variable effect on those parameters on the drug adsorption and to select the optimum adsorption parameters. The factors affecting the adsorption as well as the high and low levels were selected according to preliminary experiments.

Throughout this study, aliquots of $25 \mathrm{~mL}$ of buffered solutions of each cephalosporin with different $\mathrm{pH}$ ranges

Table 1 Mean recovery of the selected antibiotics using Oasis HLB cartridges

\begin{tabular}{llll}
\hline $\begin{array}{l}\text { Spiking } \\
\text { level }^{\mathrm{a}}\end{array}$ & $\begin{array}{l}\text { Cefadroxil } \\
\text { Recovery\% } \pm \text { S.D }\end{array}$ & $\begin{array}{l}\text { Cefprozil } \\
\text { Recovery\% } \pm \text { S.D }\end{array}$ & $\begin{array}{l}\text { Cefradine } \\
\text { Recovery\% } \pm \text { S.D }\end{array}$ \\
\hline 10 & $87.15 \pm 0.99$ & $81.50 \pm 1.99$ & $90.20 \pm 0.97$ \\
100 & $89.26 \pm 1.88$ & $93.50 \pm 0.95$ & $94.38 \pm 1.09$ \\
\hline
\end{tabular}

${ }^{\mathrm{a}}$ Concentration in $\mu \mathrm{g} / \mathrm{ml}$

${ }^{\mathrm{b}}$ Average of three experiments/SD is the standard deviation
$(4,6$, and 8) and different concentrations of MSN (0.5$1.5 \mathrm{~g} / \mathrm{L})$ were placed in a $100-\mathrm{mL}$ beaker with continuous magnetic stirring at $160 \mathrm{rpm}$ at $25^{\circ} \mathrm{C}$; samples were filtered through a $0.2-\mu \mathrm{m}$ syringe filter prior to their injection in HPLC.

\section{Adsorption kinetics and isotherm of cephalosporins on MSN}

The developed HPLC method investigated the adsorption kinetics and isotherm of cephalosporins, and the rate constants $\left(K_{\mathrm{Obs}}\right)$ were calculated at the optimum conditions. The kinetic assays were carried out in 100-mL Erlenmeyer flasks, where $25 \mathrm{~mL}$ of each cephalosporin solution with known concentration $100 \mathrm{mg} / \mathrm{L}$ and initial pH 5 were put in contact with $1 \mathrm{~g}$ of adsorbents. The flasks were stirred for a selected time $(10,20$, $30,40,50$, and $60 \mathrm{~min}$ ).

The adsorption of each cephalosporin on MSN was studied using the batch equilibrium experiments, the optimum amount of adsorbent $(1 \mathrm{~g} / \mathrm{L})$, and different concentrations of each drug were used. The initial concentration of each drug is in the rage of $50-200 \mathrm{mg} / \mathrm{L}$. The concentration of the drugs in the solution was determined by substitution in the regression equation. The amount of drug adsorbed at time $t, q_{t}(\mathrm{mg} / \mathrm{g})$, was calculated using Eq. (1):

$$
q_{t=\frac{\left(C_{o}-C_{t}\right) V}{m}}
$$

where $q_{t}=$ amount of drug adsorbed on adsorbent at any time $(\mathrm{mg} / \mathrm{g}), C o=$ initial concentration $(\mathrm{mg} / \mathrm{L}), C_{e}=$ concentration of the drug in solution at equilibrium (mg/L), $m=$ mass of adsorbent used (g), and $V=$ volume of drug solution (L).

The amount of drug adsorbed qe (mg/g) was calculated using Eq. (2):

$$
q e=\frac{(\mathrm{Co}-\mathrm{Ce}) V}{m}
$$

where $q_{e}=$ amount of drug adsorbed on adsorbent at equilibrium $(\mathrm{mg} / \mathrm{g}), C o=$ initial concentration $(\mathrm{mg} / \mathrm{L}), C_{e}$ = concentration of the drug in solution at equilibrium (mg/L), $m=$ mass of adsorbent used (g), and $V=$ volume of drug solution (L). 


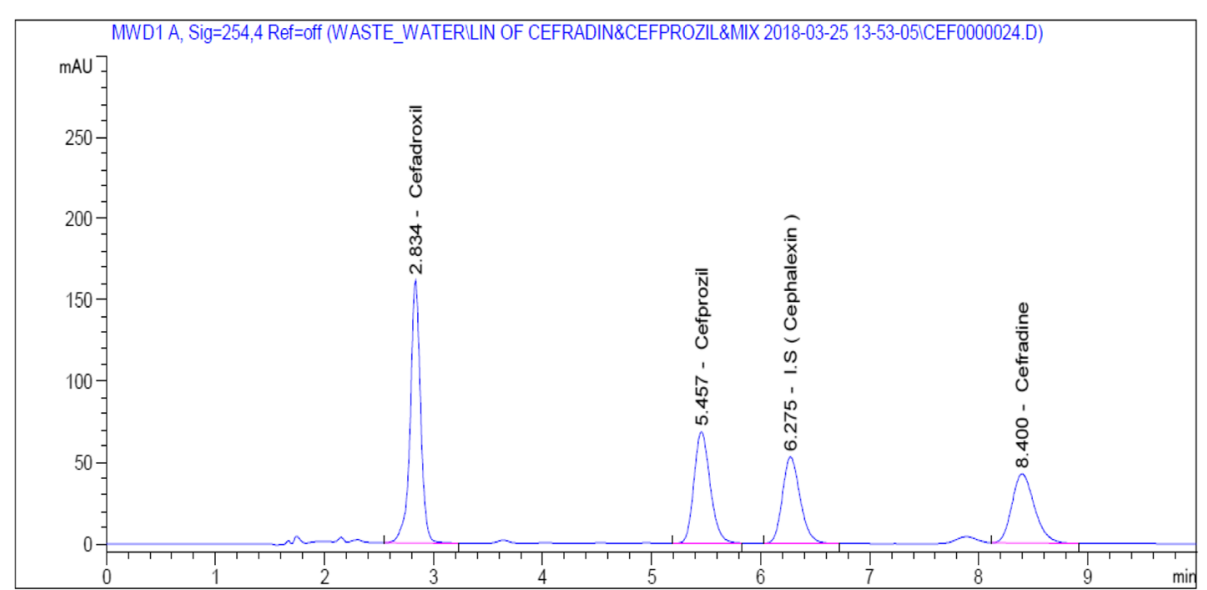

Fig. 2 Chromatogram of separation of cefadroxil, cefprozil, and cefradine using acidified water $(\mathrm{pH} 2.5)$ to methanol to acetonitrile (82:12:6, $v / \mathrm{v})$, with acid as a mobile phase and cephalexin as the internal standard

\section{Results and discussion}

In this study, high-performance level chromatography was chosen for the tracing of three structurally related cephalosporins (cefadroxil, cefprozil, and cefradine) (Fig. 1) in pharmaceutical wastewater and for tracking their removal from water by adsorption technique, as the prolonged exposure of bacteria to even low concentrations of those antibiotics may result in selective proliferation of resistant microorganisms.

\section{Extraction and clean-up (SPE)}

Extraction and pre-concentration step must precede the chromatographic analysis due to analyte presence in complex environmental samples, and several factors such as $\mathrm{pH}$, type of eluent, and cartridges could influence the recovery; in this study, optimum conditions were applied for extraction of the selected cephalosporins from water samples as reported previously by Wang et al. (Wang et al. 2011). Table 1 presents the recoveries that were obtained for each cephalosporin after spiking it to water samples at two different levels and performing the complete analytical procedure with calculating

Table 2 System suitability parameters of the proposed HPLC-UV method

\begin{tabular}{lllll}
\hline Parameters & Cefadroxil & Cefprozil & $\begin{array}{l}\text { Cephalexin } \\
(\mathrm{IS})\end{array}$ & Cefradine \\
\hline Retention time $\left(t_{R}\right)$ & 2.84 & 5.46 & 6.27 & 8.4 \\
$K^{\prime}$ (capacity factor) & 1.44 & 3.7 & 4.41 & 6.24 \\
Number of plates $(N)$ & 5662 & 7019 & 7544 & 8122 \\
Height equivalent to the & 0.0018 & 0.0014 & 0.0013 & 0.0012 \\
theoretical plates (HETP) & & & & 0.79 \\
Tailing & 0.85 & 0.80 & 0.8 & \\
Resolution $(R s)$ & 13.02 & 3 & 6.64 & \\
Selectivity & 2.64 & 1.06 & 1.38 & \\
\hline
\end{tabular}

recoveries, as the percentage of the analyte extracted to the total analyte amount.

\section{Chromatographic method}

The preliminary experiments revealed that $254 \mathrm{~nm}$ was the optimum analytical wavelength for the selected cephalosporin antibiotics, after trying different wavelengths (230, 254, and 278), since both good chromatographic response and high sensitivity were achieved.

In this study, acidified water with orthophosphoric acid ( $\mathrm{pH} 2.5)$ to methanol to acetonitrile $(82: 12: 6, v / v)$ showed the best separation results in comparison with other systems applied, as on using one organic solvent, the mixture was not completely resolved, and upon using acetate buffer ( $\mathrm{pH}$ 2.5), the baseline showed noise as illustrated in Additional file 1: Figure S2.

Table 3 Assay parameters and method validation obtained by applying the proposed HPLC-UV method

\begin{tabular}{llll}
\hline Parameters & Cefadroxil & Cefprozil & Cefradine \\
\hline $\begin{array}{l}\text { Concentration range }(\mu \mathrm{g} / \\
\mathrm{mL})\end{array}$ & $10-200$ & $10-200$ & $10-200$ \\
Slope & 0.0257 & 0.0142 & 0.013 \\
Intercept & 0.0315 & 0.0031 & 0.0222 \\
Mean $^{\mathrm{a}} \pm \mathrm{SD}$ & $99.71 \pm$ & $100.47 \pm$ & $99.73 \pm 0.70$ \\
& 1.58 & 1.55 & \\
LOD $(\mu \mathrm{g} / \mathrm{mL})^{\mathrm{LOQ}}(\mu \mathrm{g} / \mathrm{mL})$ & 3 & 4 & 3 \\
$R^{2}$ & 10 & 10 & 10 \\
Accuracy $^{2}$ & 0.9997 & 0.9995 & 0.9999 \\
Inter-day precision $^{\mathrm{b}}$ & $99.75 \pm$ & $99.90 \pm 0.77$ & $100.21 \pm$ \\
Intra-day precision $^{\mathrm{b}}$ & 1.01 & & 0.246 \\
\hline
\end{tabular}

${ }^{\mathrm{a} A v e r a g e}$ of the six concentrations repeated three times

${ }^{b}$ Relative standard deviation of the three concentrations $(50,100$, and $150 \mu \mathrm{g}$ $\left.\mathrm{mL}^{-1}\right)$ repeated three times $(n=9)$ 
Table 4 Concentrations of three cephalosporin antibiotics in pharmaceutical wastewater samples

\begin{tabular}{llll}
\hline Sample number & Cefadroxil & Cefprozil & Cefradine \\
\hline 1 & $18.25 \mu \mathrm{g} / \mathrm{mL}$ & N.D & N.D \\
2 & N.D & $33.74 \mu \mathrm{g} / \mathrm{mL}$ & N.D \\
3 & N.D & N.D & $545.9 \mu \mathrm{g} / \mathrm{mL}^{a}$ \\
4 & N.D & N.D & N.D \\
5 & N.D & N.D & N.D \\
\hline
\end{tabular}

N.D not detected

${ }^{a}$ The concentration was obtained by sample dilution (one part sample to three parts pure water)

Different flow rates were tried, and the results showed that the satisfactory chromatogram was achieved with a flow rate of $1.5 \mathrm{ml} / \mathrm{min}$ as shown in Fig. 2. So far, no interfering compounds were co-eluted from the water samples, which may be attributed to different reasons: the specific cephalosporin antibiotics structure and also the optimized SPE extraction technique and the selected mobile phase.

System suitability parameters for the three drugs were calculated and compared to reference values (United States Pharmacopeia (2009)).The results were found to be within the acceptable range as illustrated in Table 2 . The retention time of cefadroxil appeared at $2.8 \mathrm{~min}$, cefprozil at $5.5 \mathrm{~min}$, and cefradine at $8.4 \mathrm{~min}$.

The calibration curves for the three cephalosporins were constructed by plotting the relative peak area, ratio of analyte to that of cephalexin (I.S) at $254 \mathrm{~nm}$ versus the corresponding concentration for the three drugs. The linear relationships were obtained in the range 10$200 \mu \mathrm{g} \mathrm{mL}^{-1}$ for cefadroxil, cefprozil, and cefradine, and the linearity was calculated by using 6-point calibration curves. The limits of detection (LOD) were determined by experiments in the range of $3-4 \mu \mathrm{g} / \mathrm{mL}$, and limits of quantification (LOQ) were set at the lower end of the linearity; the corresponding concentration ranges, calibration equations, and other statistical parameters were shown in Table 3.

Table 5 Factorial design for experiments employed for cephalosporins adsorption and results obtained using HPLC-UV assay

\begin{tabular}{lllllll}
\hline Run & $\mathrm{pH}$ & $\begin{array}{l}\text { Initial } \\
\text { concentration } \\
(\mathrm{g} / \mathrm{L})\end{array}$ & $\begin{array}{l}\text { Adsorbent } \\
\text { loading } \\
\text { dose }(\mathrm{g} / \mathrm{L})\end{array}$ & $\begin{array}{l}\text { Cefadroxil } \\
\text { removal } \\
(\%)\end{array}$ & $\begin{array}{l}\text { Cefprozil } \\
\text { removal } \\
(\%)\end{array}$ & $\begin{array}{l}\text { Cefradine } \\
\text { removal } \\
(\%)\end{array}$ \\
\hline 1 & 6 & 0.11 & 1 & 54.4 & 58.3 & 55.3 \\
2 & 6 & 0.11 & 1 & 55.2 & 59.3 & 54.23 \\
3 & 4 & 0.02 & 1.5 & 43.6 & 47.01 & 41.2 \\
4 & 8 & 0.2 & 1.5 & 35.4 & 33.54 & 34.8 \\
5 & 6 & 0.11 & 1 & 55.9 & 60.25 & 53.89 \\
6 & 4 & 0.2 & 0.5 & 38.12 & 38.2 & 37.2 \\
7 & 8 & 0.02 & 0.5 & 32.2 & 30.15 & 29.3 \\
\hline
\end{tabular}

Five different concentrations of the pure form of each cephalosporin were determined in three replicates using the proposed chromatographic method in order to study the accuracy of the methods, while the precision of the proposed methods was determined by the analysis of three different concentrations of pure drugs either on the same day or on three consecutive days. The accuracy expressed as recovery percentage and precision as RSD $\%$ (Table 3).

\section{Application of method \\ Application on wastewater samples}

The developed chromatographic method was applied for determining the selected cephalosporins in water samples from the pharmaceutical industry, and the samples were analyzed under the previous conditions described after applying the mentioned SPE technique. Identification of target compounds was done by comparing retention time values of the standards and compounds in wastewater samples, and results were stated in Table 4.

\section{Application for adsorption studies}

The gradual decrease of each cephalosporin (cefadroxil, cefprozil, and cefradine) concentration was monitored over time using the developed chromatographic method. Results indicated that the maximum adsorption percentages were $56.5 \%, 58.28 \%$, and $64.74 \%$, for cefadroxil, cefprozil, and cefradine respectively at the adoption equilibrium.

\section{Experimental design}

Three factors were used to employ the fractional factorial design: $\mathrm{pH}$, initial drug concentration, and adsorbent concentration with two levels for each factor to get the best conditions $-\mathrm{pH} \mathrm{4}, 8 ; 20,200 \mathrm{mg} / \mathrm{L}$ as initial drug concentration; and $0.5,1.5 \mathrm{~g} / \mathrm{L}$ MSN concentration. The selection of optimum experimental conditions set was based on the relative significance of the studied factors and their interactions which was necessary to get the maximum adsorption; the developed chromatographic technique was used for sample analysis and percentage of drug adsorption was chosen as the response (Table 5). Analysis results of all samples were plotted versus run number (Additional file 1: Figure S3).

\section{Analysis of the results}

The $R^{2}$ statistics of the factorial model was equal to $0.984,0.9981$, and 0.9984 for cefadroxil, cefprozil, and cefradine, respectively, which is considered satisfactory. The $R^{2}$ value approaching 1 indicates that the model explained a large proportion of the variation in the observed values. Model adequacy checking is conducted to justify whether the fitted model provides the approximation to the true system was adequate and none of the least squares regression assumptions are disobeyed; the 
Table 6 ANOVA for the selected factorial model

\begin{tabular}{|c|c|c|c|c|c|c|c|c|c|c|c|c|c|c|c|}
\hline \multirow[t]{2}{*}{ Source } & \multicolumn{5}{|c|}{ Cefadroxil } & \multicolumn{5}{|l|}{ Cefprozil } & \multicolumn{5}{|c|}{ Cefradine } \\
\hline & $\begin{array}{l}\text { Sum of } \\
\text { squares }\end{array}$ & $\begin{array}{l}\text { Degree of } \\
\text { freedom }\end{array}$ & $\begin{array}{l}\text { Mean } \\
\text { squares }\end{array}$ & $\begin{array}{l}F \\
\text { value }\end{array}$ & $\begin{array}{l}p \\
\text { value }\end{array}$ & $\begin{array}{l}\text { Sum of } \\
\text { squares }\end{array}$ & $\begin{array}{l}\text { Degree of } \\
\text { freedom }\end{array}$ & $\begin{array}{l}\text { Mean } \\
\text { squares }\end{array}$ & $\begin{array}{l}F \\
\text { value }\end{array}$ & $\begin{array}{l}p \\
\text { value }\end{array}$ & $\begin{array}{l}\text { Sum of } \\
\text { squares }\end{array}$ & $\begin{array}{l}\text { Degree of } \\
\text { freedom }\end{array}$ & $\begin{array}{l}\text { Mean } \\
\text { squares }\end{array}$ & $\begin{array}{l}F \\
\text { value }\end{array}$ & $\begin{array}{l}p \\
\text { value }\end{array}$ \\
\hline Model & 615.37 & 4 & 153.84 & 273.09 & 0.0037 & 994.45 & 4 & 994.45 & 261.47 & 0.0038 & 683.26 & 4 & 683.26 & 315.49 & 0.0032 \\
\hline A & 49.84 & 1 & 49.84 & 88.48 & 0.0111 & 115.67 & 1 & 115.67 & 121.65 & 0.0081 & 51.12 & 1 & 51.12 & 94.42 & .0104 \\
\hline B & 1.30 & 1 & 1.30 & 2.31 & 0.2681 & 7.32 & 1 & 7.32 & 7.70 & 0.1091 & 0.56 & 1 & 0.56 & 1.04 & 0.4153 \\
\hline C & 18.84 & 1 & 18.84 & 33.44 & 0.0286 & 37.15 & 1 & 37.15 & 39.07 & 0.0247 & 22.56 & 1 & 22.56 & 41.67 & 0.0232 \\
\hline$A B C$ & 545.39 & 1 & 545.39 & 968.16 & 0.0010 & 834.31 & 1 & 834.31 & 877.45 & 0.0011 & 609.02 & 1 & 609.02 & 1124.8 & 0.0009 \\
\hline $\begin{array}{l}\text { Pure } \\
\text { error }\end{array}$ & 1.13 & 2 & 0.56 & & & 1.90 & 2 & 0.95 & & & 1.08 & 2 & 0.54 & & \\
\hline $\begin{array}{l}\text { Cor } \\
\text { total }\end{array}$ & 616.50 & 6 & & & & 996.35 & 6 & & & & 684.35 & 6 & & & \\
\hline
\end{tabular}

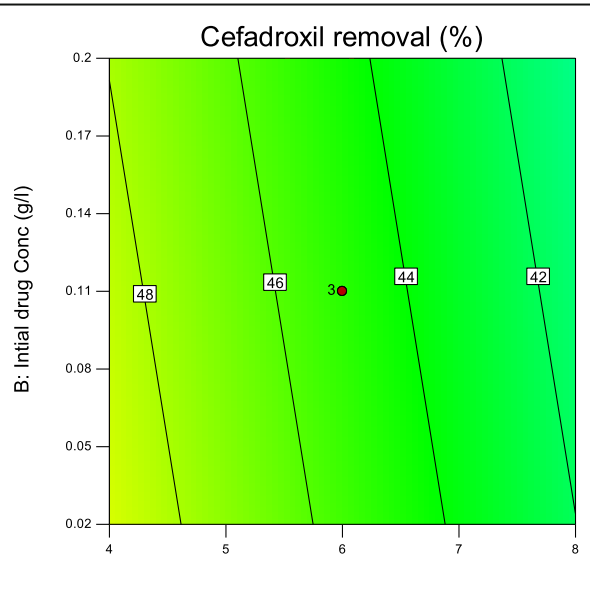

A: $\mathrm{pH}$

a
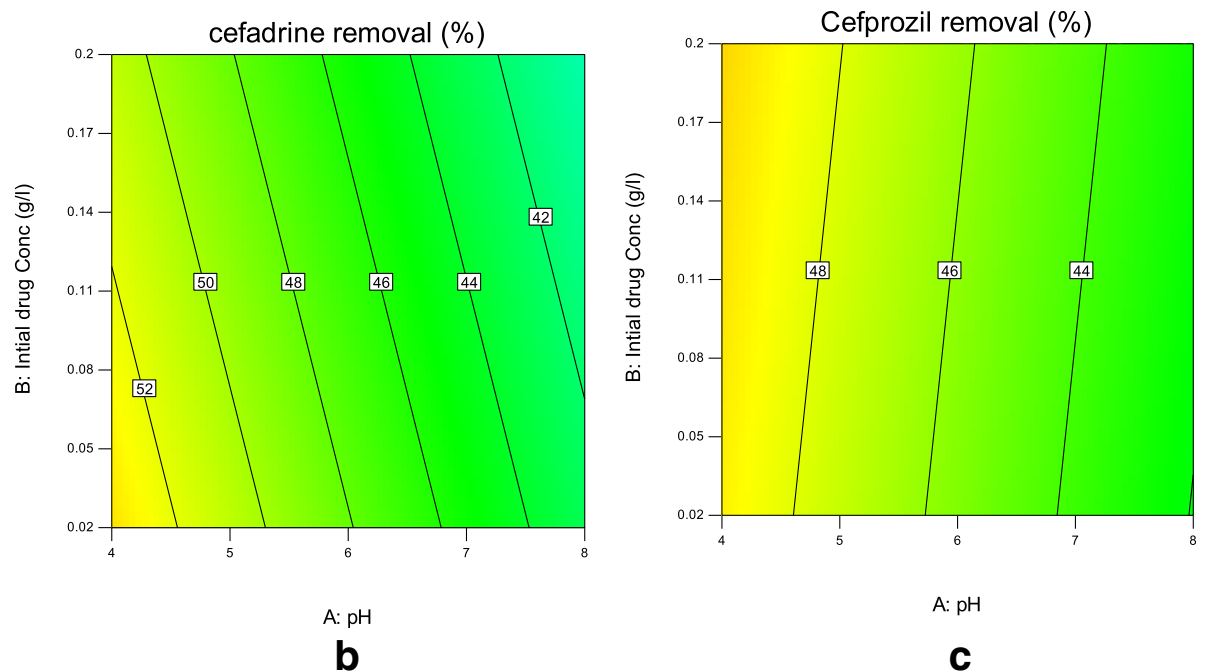

Fig. 3 Interaction of pH with an initial concentration of a cefadroxil, $\mathbf{b}$ cefprozil, and c cefradine at MSN loading dose $1 \mathrm{~g} / \mathrm{L}$ 


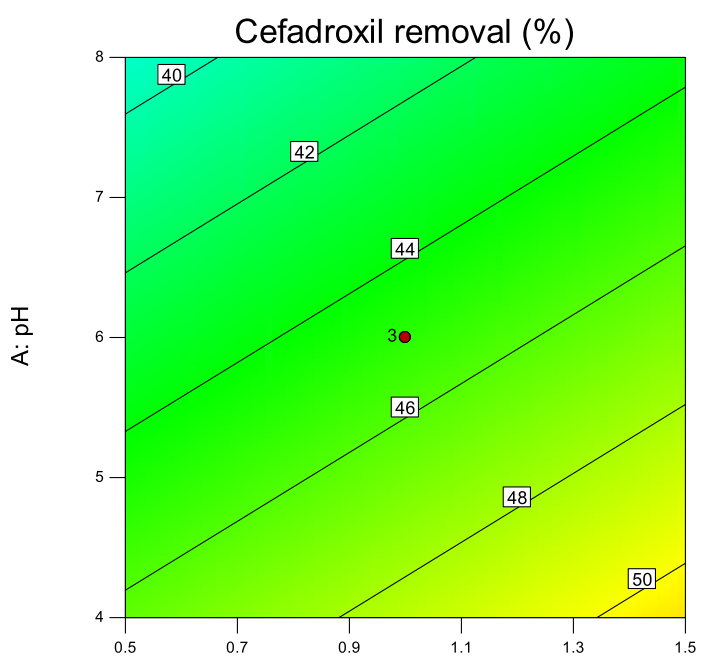

C: Adsorbent conc (g/l)

a

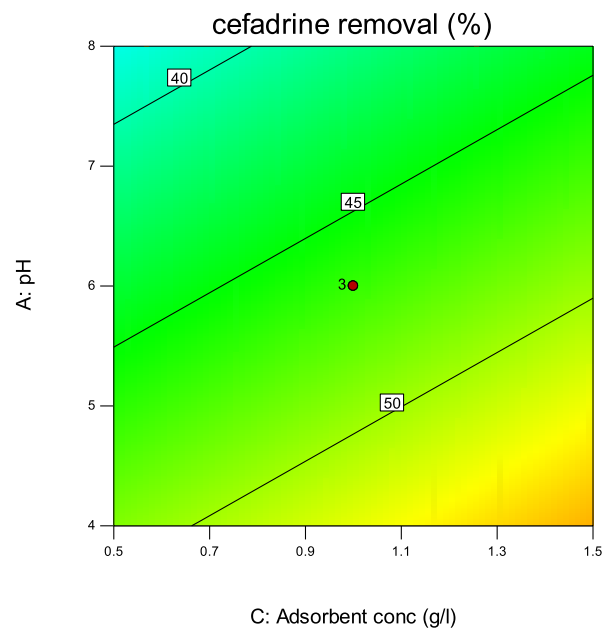

b

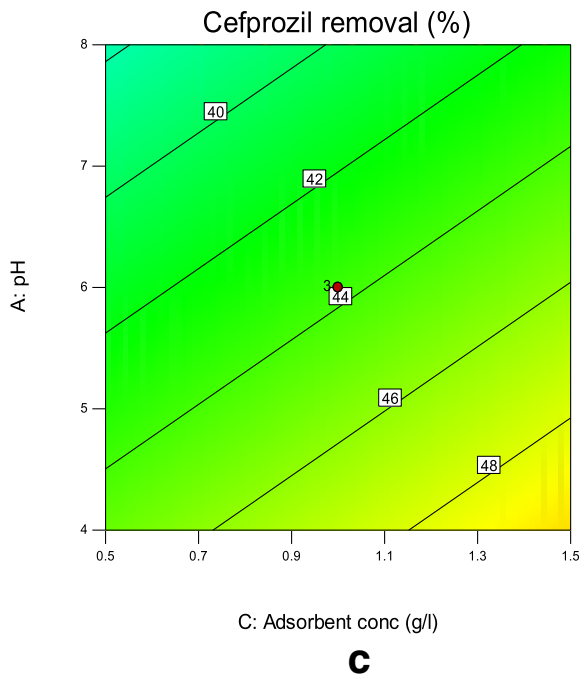

Fig. 4 Interaction of pH with MSN loading dose at constant initial concentration of $0.12 \mathrm{~g} / \mathrm{L}$ for a cefadroxil, $\mathbf{b}$ cefprozil, and $\mathbf{c}$ cefradine

normality assumption was checked by the normal probability plot of residuals, the residual plot approximates a straight line, and all the points lie on the diagonal, so the normality assumption seemed to be satisfactory (Additional file 1: Figure S4), while the plot of the residuals versus predicted response suggested a random scatter, suggesting a constant variance (Additional file 1: Figure S5).

\section{Studied factors and their interaction}

The 95\% confidence level $(P<0.05)$ was used to determine the statistical significance in all analyses; numerous descriptive statistics such as the $p$ value, $F$ value, and the degree of freedom (df) were also used to assess the results. As shown in Table 6, $\mathrm{pH}$ value (A) was a highly significant parameter with $p<0.0012$, as well as the initial concentration (B), and both are significant parameters with a negative effect; the dose of adsorbent (C) was found significant too but with a positive effect.

The two-dimensional (2D) contour plots are the most useful way to reveal the reaction system conditions; they are graphical representations of the regression equation, produced by Design-Expert software, and plotted for reaction condition optimization. In those plots, the response functions of two factors are presented while the third factor is fixed at a certain level. Due to the high similarity and common functional group between cefadroxil, cefprozil, and cefradine, they have the same reaction towards the system conditions.

Figure 3 shows the $\mathrm{pH}$ and initial cephalosporin concentration interaction on the removal efficiency. The 


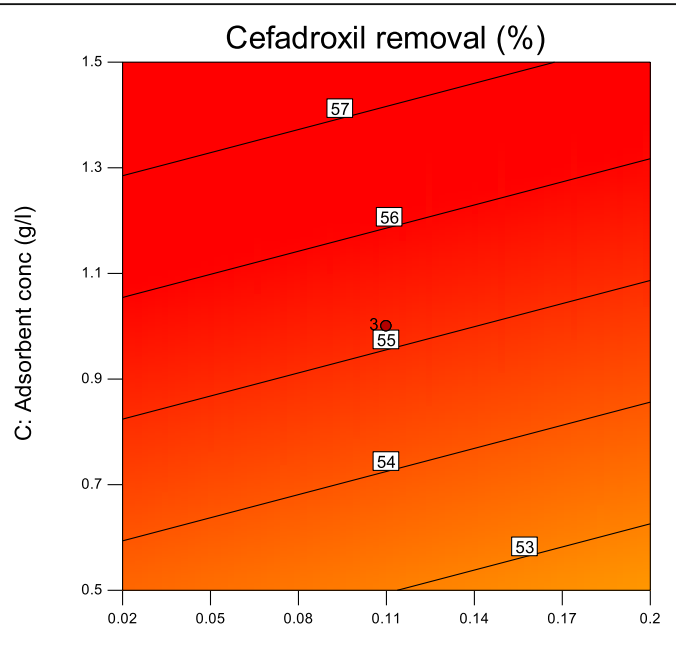

B: Intial drug Conc (g/l)

a
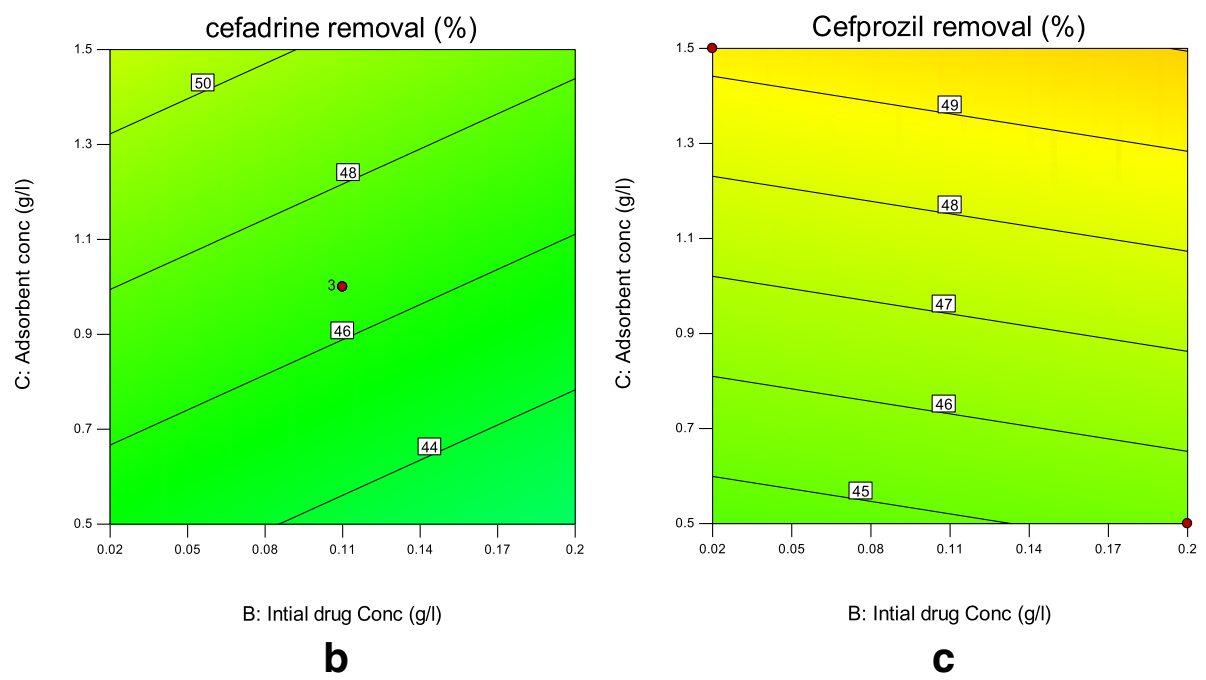

Fig. 5 Interaction of MSN loading dose with an initial concentration of a cefadroxil, b cefprozil, and c cefradine at constant pH 6

decrease in the $\mathrm{pH}$ increased the removal of cephalosporins regardless of the concentration of the adsorbate, and the maximum removal was achieved at a $\mathrm{pH}$ range of $4-5$.

The interaction between the silica concentration and $\mathrm{pH}$ on cephalosporin removal (Fig. 4) showed that more silica was needed to enhance the removal rate at alkaline $\mathrm{pH}$, as the surface of silica become negatively charged and weaken the interaction between it and the adsorbate.

As can be seen in Fig. 5, the increase of the initial concentration of the cephalosporins with decrease in silica loading dose slowed the removal rate, which resulted from the saturation of the adsorbent active sites; the adsorption power could be improved by increasing the MSN concentration and further dilution of samples to increase the availability of more free adsorption active site for the adsorption process.

Another experiment was carried out using the optimum predicted levels by the design, which were $\mathrm{pH} 5$ and MSN $0.95 \mathrm{~g} / \mathrm{L}$ on the collected industrial wastewater samples. The correspondence between the predicted and experimental results at the optimum levels was $96.78 \%, 95.15 \%$, and $101.93 \%$ for cefadroxil, cefprozil, and cefradine, respectively, which proved the validity of the design.

\section{Kinetics of adsorption}

The adsorption of the three cephalosporins occurred rapidly at the beginning due to the availability of numerous binding sites at the initial stage, and then the rate decreased by increasing the adsorption time; it reached 


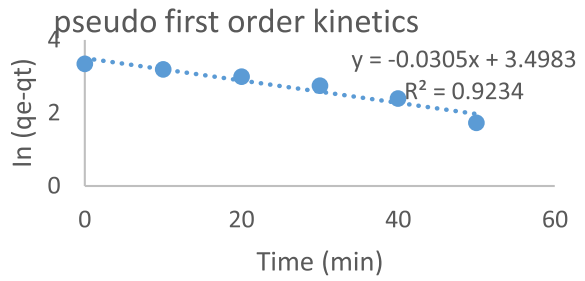

a

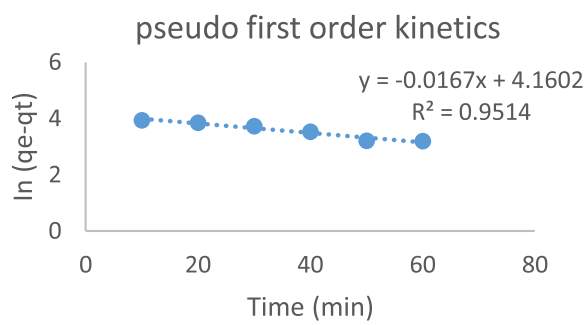

C

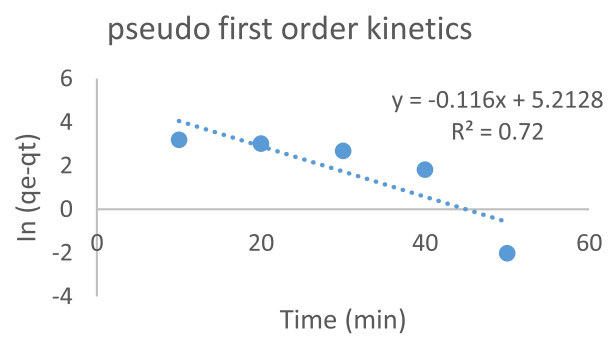

e

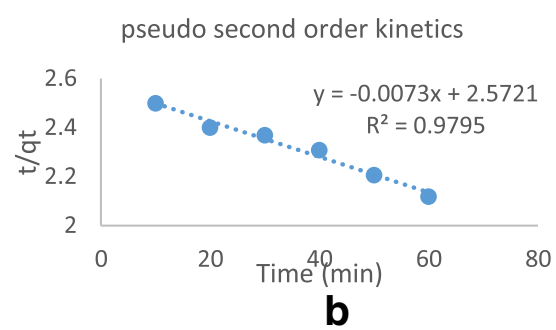

b

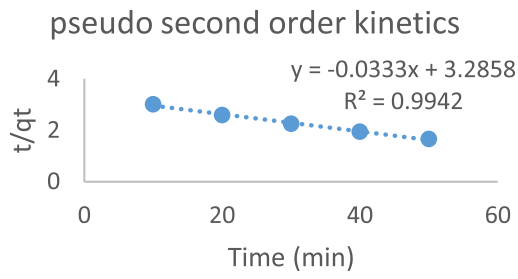

d
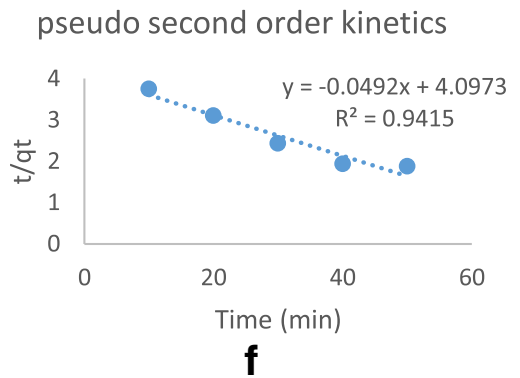

Fig. 6 a Pseudo-first-order adsorption kinetics of cefadroxil, b pseudo-second-order adsorption kinetics of cefadroxil, c pseudo-first-order adsorption kinetics of cefprozil, $\mathbf{d}$ pseudo-second-order adsorption kinetics of cefprozil, e pseudo-first-order adsorption kinetics of cefradine, and $\mathbf{f}$ pseudo-second-order adsorption kinetics of cefradine on MSN particle at optimum conditions

equilibrium within $180 \mathrm{~min}$; mesoporous silica needed shorter contact time than that required for the adsorption on activated charcoal (Mestre et al. 2007) and multi-walled carbon nanotubes (Jafari et al. 2011). The well-ordered mesoporous silica structure facilitates the drug diffusion into the pores and adsorbed on the surface in a shorter time, which makes MSN a preferable adsorbent for the treatment process for a sample containing cephalosporins.

Adsorption rate has been investigated by using two kinetic models which are the pseudo-first-order (3) and pseudo-second-order (4) equations:

$$
\begin{aligned}
& \operatorname{In}\left(\frac{q e-q t}{q_{e}}\right)=-k_{1} t \\
& \frac{t}{q}=\frac{1}{k_{2} q_{e}{ }^{2}}+\frac{t}{q_{e}}
\end{aligned}
$$

where $q t$ and $q e$ are the amounts of solute sorbed per mass of sorbent $\left(\mathrm{mg} \mathrm{g}^{-1}\right)$ at any time and equilibrium, respectively (calculated previously); $k_{1}$ and $k_{2}$ are the rate constant of first-order sorption and second-order sorption respectively $\left(\mathrm{min}^{-1}\right)$.

By comparing the $R^{2}$ values derived from both models (Fig. 6), it is found that the pseudo-secondorder kinetic model fits better with the kinetic data than the pseudo-first-order kinetic model, which was then used for $k$ calculation; they were $2.13 \times 10^{-5}$, $5.8 \times 10^{-4}$, and $3.4 \times 10^{-4}$ for cefadroxil, cefprozil, and cefradine, respectively.

\section{Adsorption isotherms}

Numerous isotherm equations can be used for adsorption data analysis; the most common isotherm equations are the theoretical equilibrium isotherm (Langmuir) (Langmuir 1916) and the Freundlich (Freundlich 1907) (empirical equilibrium isotherm). The linear forms of these equilibrium isotherms are displayed as Eqs. (5) and (6) respectively: 
langmuir isotherm

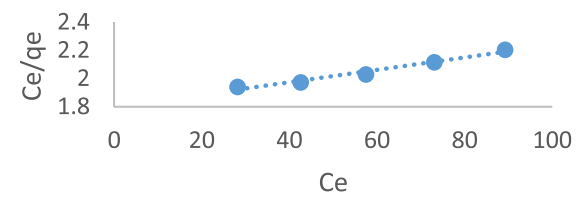

a

langmuir isotherm
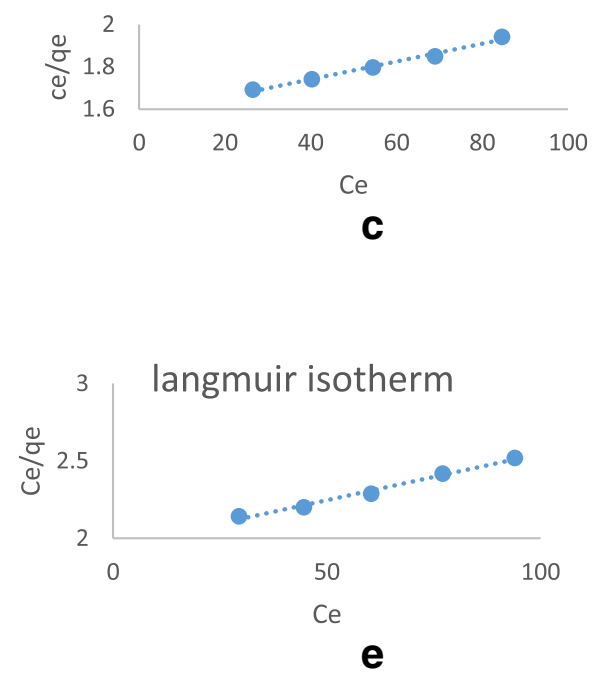

Fredlich isotherm

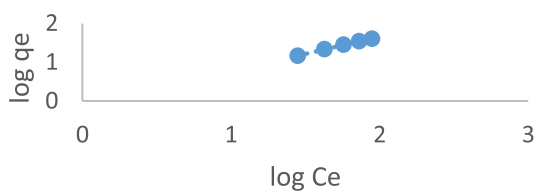

b

Freundlich isotherm

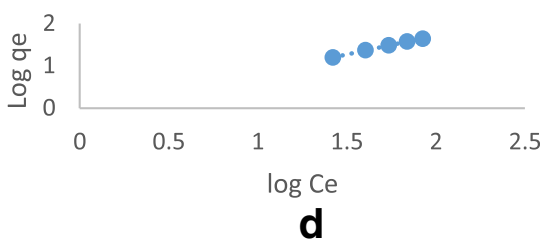

Freundlich isotherm

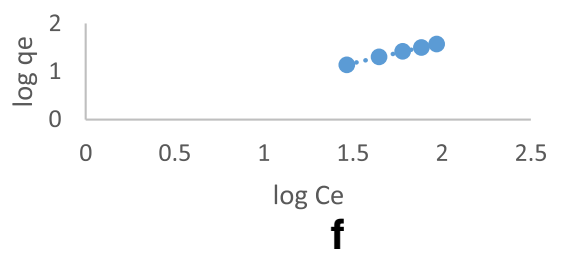

Fig. 7 a Langmuir adsorption isotherm of cefadroxil, b Freundlich adsorption isotherm of cefadroxil, c Langmuir adsorption isotherm of cefprozil, $\mathbf{d}$ Freundlich adsorption isotherm of cefprozil, e Langmuir adsorption isotherm of cefradine, and $\mathbf{f}$ Freundlich adsorption isotherm of cefradine on MSN at optimum conditions

$$
\begin{aligned}
& \frac{1}{q_{e}}=\frac{1}{q_{m} K_{L C_{e}}}+\frac{1}{q_{m}} \\
& \log q_{e}=\log K_{F}+\frac{1}{n} \log C_{e}
\end{aligned}
$$

where $q_{\mathrm{m}}\left(\mathrm{mg} \mathrm{g}^{-1}\right)$ represent the maximum adsorption capacity, $q_{\mathrm{e}}\left(\mathrm{mg} \mathrm{g}^{-1}\right)$ is the amount of drug adsorbed, $C_{\mathrm{e}}$ $\left(\mathrm{mg} \mathrm{L}^{-1}\right)$ is the equilibrium drug concentration, $K_{F}$ and $n$

Table $\mathbf{7}$ Isotherm parameters obtained by fitting equilibrium data with Langmuir and Freundlich isotherms for cephalosporins adsorption on MSN

\begin{tabular}{lllllllll}
\hline Cephalosporin & \multicolumn{2}{l}{ Freundlich } & & \multicolumn{2}{l}{ Langmuir } \\
\cline { 2 - 3 } & $K_{F}$ & $n$ & $R^{2}$ & & $K_{L}$ & $q_{m}(\mu \mathrm{g} / \mathrm{g})$ & $R^{2}$ \\
\hline Cefadroxil & 1.32 & 1.12 & 0.998 & & 0.0024 & 227.3 & 0.979 \\
Cefprozil & 1.12 & 1.15 & 0.999 & & 0.0026 & 238 & 0.988 \\
Cefradine & 1.30 & 1.16 & 0.998 & & 0.003 & 166.6 & 0.989 \\
\hline
\end{tabular}

are the Freundlich constants, and $K_{L}\left(\mathrm{~L} \mathrm{mg}^{-1}\right)$ is the Langmuir constant.

The adsorption data at room temperature for the three cephalosporins on to MSN was used to fit linearized expressions of Langmuir and Freundlich. The linearity obtained was good in both cases as shown in isotherm plots (Fig. 7).

The parameters related to the Langmuir and Freundlich isotherms were summarized in Table 7; the $R^{2}$ values showed that the adsorption isotherm of the three cephalosporins fitted to the Freundlich equation was better than that to the Langmuir, and the high $K_{F}$ value described the high affinity of the cephalosporins towards used mesoporous silica.

\section{Conclusion}

This research described and linked two important, promising areas together, developing a chromatographic method for cephalosporin monitoring in real wastewater samples after their clean-up using solid phase extraction 
technique and applying this developed method for testing the efficiency of MSN as an adsorbent for three cephalosporins (cefadroxil, cefprozil, and cefradine) for the removal from industrial wastewater. The optimization of the adsorption process was done by using a factorial design to find out the relative significance, studied factor effects, and interactions $(\mathrm{pH}$, cephalosporin initial concentration, and MSN loading dose) to achieve the best-optimized system.

The adsorption kinetics and isotherm of cephalosporins on MSN were studies at the optimum condition; it was found from the results that it obeyed the pseudo-secondorder kinetics and Freundlich isotherm model, and they adsorbed on MSN with a great affinity and relatively short time in comparison with other adsorbents. This treatment method is recommended to be used by the pharmaceutical industry on a large scale as an environmental friendly method for in-site treatment of water highly loaded with cephalosporins before its discharge.

\section{Additional file}

Additional file 1: Figure S1. TEM micrograph of mesoporous silica nanoparticles. Figure S2. Chromatogram of cefadroxil, cefprozil and cefadrine on using (a) phosphate buffer: methanol (80:20) as a mobile phase and cephalexin as internal standard and (b) acetate buffer acetonitrile: methanol (78:9:13). Figure S3. Percentage of treatment by adsorption vs the sample number for (a) cefadroxil, (b) cefprozil and (c) cefadrine. Figure S4. Normal plot of residuals for the factorial design, (a) for cefadroxil, (b) cefprozil and (c) cefradine percentage treatment. Figure S5. Plot of residuals vs predicted response for factorial design, (a) percentage of treatment of cefadroxil, (b) cefprozil and (c) cefadrine. (DOCX $243 \mathrm{~kb}$ )

\section{Abbreviations}

EDTA: Ethylenediaminetetraacetic acid; EPA: Environmental Protection Agency; HLB: Hydrophilic-lipophilic balance; HPLC: High-performance liquid chromatography; MSN: Mesoporous silica nanoparticles; RSD: Relative standard deviation; SPE: Solid phase extraction; UV: Ultraviolet

\section{Acknowledgements}

Not applicable for that section.

\section{Funding}

Not applicable for that section.

\section{Availability of data and materials}

All data generated or analyzed during this study are included in this published article [and its supplementary information files].

\section{Authors' contributions}

HT collected the sample and analyzed and interpreted the adsorption data regarding the use of mesoporous silica for treatment methods. AY optimized the chromatographic conditions for cephalosporins detection. SM revised the statistical analysis of the results. YS revised the results section. All authors read and approved the final manuscript.

\section{Competing interests}

The authors declare that they have no competing interests.

\section{Publisher's Note}

Springer Nature remains neutral with regard to jurisdictional claims in published maps and institutional affiliations.

\section{Author details}

${ }^{1}$ Analytical Chemistry Department, Faculty of Pharmacy, October University for Modern Sciences and Arts (MSA), 6th of October City 11787, Egypt. ${ }^{2}$ Analytical Chemistry Department, Faculty of Pharmacy, Cairo University, Kasr-El Aini 13 Street, Cairo 11562, Egypt. ${ }^{3}$ Chemistry Department, School of Pharmacy and pharmaceutical industries, Badr University in Cairo, Badr City, Cairo 11829, Egypt.

Received: 16 March 2019 Accepted: 5 May 2019

Published online: 16 May 2019

\section{References}

Carabineiro S, Thavorn-Amornsri T, Pereira M, Figueiredo J. Adsorption of ciprofloxacin on surface-modified carbon materials. Water Res. 2011;45:4583-91.

Carabineiro S, Thavorn-Amornsri T, Pereira M, Serp P, Figueiredo J. Comparison between activated carbon, carbon xerogel and carbon nanotubes for the adsorption of the antibiotic ciprofloxacin. Catal Today. 2012;186:29-34.

David Duncan FH, Michelle Walker (2007) EPA guidelines: regulatory monitoring and testing water and wastewater sampling. South australia.

De Lima LS, Araujo MDM, Quináia SP, Migliorine DW, Garcia JR. Adsorption modeling of $\mathrm{Cr}$, $\mathrm{Cd}$ and $\mathrm{Cu}$ on activated carbon of different origins by using fractional factorial design. Chem Eng J. 2011;166:881-9.

Dębska J, Kot-Wasik A, Namieśnik J. Fate and analysis of pharmaceutical residues in the aquatic environment. Crit Rev Anal Chem. 2004;34:51-67.

Duan $\mathrm{H}$. Study on the treatment process of wastewater from cephalosporin production JSD 2; 2009. p. 133.

Fakhri A, Adami S. Adsorption and thermodynamic study of Cephalosporins antibiotics from aqueous solution onto MgO nanoparticles. J Taiwan Inst Chem. 2014;45:1001-6.

Fakhri A, Rashidi S, Asif M, Tyagi I, Agarwal S, Gupta VK. Dynamic adsorption behavior and mechanism of Cefotaxime, Cefradine and Cefazolin antibiotics on CdS-MWCNT nanocomposites. J Mol Liq. 2016;215:269-75.

Ferech M, Coenen S, Malhotra-Kumar S, Dvorakova K, Hendrickx E, Suetens C, Goossens H. European Surveillance of Antimicrobial Consumption (ESAC): outpatient antibiotic use in Europe. J Antimicrob Chemother. 2006;58:401-7.

Freundlich H. Über die adsorption in lösungen. Z Phys Chem. 1907:57:385-470.

Gadipelly C, Pérez-González A, Yadav GD, Ortiz I, Ibáñez R, Rathod VK, Marathe KV. Pharmaceutical industry wastewater: review of the technologies for water treatment and reuse. Ind Eng Chem Res. 2014;53:11571-92.

Geyikci F, Büyükgüngör H. Factorial experimental design for adsorption silver ions from water onto montmorillonite. Acta Geodyn Geomater. 2013;10:363-70.

Gleick PH. Dirty-water: estimated deaths from water-related diseases 2000-2020: Citeseer; Oakland. 2002.

Goossens H, Ferech M, Vander Stichele R, Elseviers M, Group EP. Outpatient antibiotic use in Europe and association with resistance: a cross-national database study. Lancet. 2005;365:579-87.

Guo R, Chen J. Application of alga-activated sludge combined system (AASCS) as a novel treatment to remove cephalosporins. Chem Eng J. 2015;260:550-6.

Harris SJ, Cormican M, Cummins E. Antimicrobial residues and antimicrobialresistant bacteria: impact on the microbial environment and risk to human health-a review. Hum Ecol Risk Assess. 2012;18:767-809.

Hue TTT, Son DC, Lan ANT, Anh NTK, Phong TK, Hiramatsu K. A simple and rapid method to measure residue of cefexime-a cephalosporin antibiotic in the wastewater of pharmaceutical production. Plant J Fac Agr Khushu U. 2014:59:169-75.

Jafari M, Aghamiri SF, Khaghanic G. Batch adsorption of cephalosporins antibiotics from aqueous solution by means of multi-walled carbon nanotubes. World Appl Sci J. 2011;14:1642-50.

Jane $\mathrm{K}$. The science and technology of industrial water treatment, reverse osmosis membrane fouling control. Boca Raton: CRC Press; 2010.

Karanfil T, Kitis M, Kilduff JE, Wigton A. Role of granular activated carbon surface chemistry on the adsorption of organic compounds. 2. Natural organic matter. Environ Sci Technol. 1999;33:3225-33.

Kümmerer K. Antibiotics in the aquatic environment-a review-part I. Chemosphere. 2009;75:417-34.

Langmuir I. The constitution and fundamental properties of solids and liquids. Part I. Solids J Am Chem Soc. 1916;38:2221-95.

Lehr JH, Keeley J. Domestic, municipal, and industrial water supply and waste disposal: Wiley; Hoboken. 2005.

Lorphensri O, Intravijit J, Sabatini DA, Kibbey TC, Osathaphan K, Saiwan C. Sorption of acetaminophen, 17a-ethynyl estradiol, nalidixic acid, and 
norfloxacin to silica, alumina, and a hydrophobic medium. Water Res. 2006; 40:1481-91.

McKay G. Design models for adsorption systems in wastewater treatment. J Chem Technol Biotechnol. 1981;31:717-31.

Meijer D, Wilting J. Trends in the organization of drug research: interfacing industry and universities. Eur J Pharm Biopharm. 1997:43:243-52.

Mestre A, Pires J, Nogueira J, Carvalho A. Activated carbons for the adsorption of ibuprofen. Carbon. 2007;45:1979-88.

Montgomery DC. Design and analysis of experiments. 9th ed. Arezona state: Wiley; 2017.

Organization WH (2017) Progress on drinking water, sanitation and hygiene.

Petrović M, Škrbić B, Živančev J, Ferrando-Climent L, Barcelo D. Determination of 81 pharmaceutical drugs by high performance liquid chromatography coupled to mass spectrometry with hybrid triple quadrupole-linear ion trap in different types of water in Serbia. Sci Total Environ. 2014:468:415-28.

Pharmacopoeia B. The Stationery Office on behalf of the Medicines and Healthcare products Regulatory Agency (MHRA)-@ Crown Copyright; 2013.

Quesada-Molina C, García-Campaña AM, del Olmo-Iruela M. Ion-paired extraction of cephalosporins in acetone prior to their analysis by capillary liquid chromatography in environmental water and meat samples. Talanta. 2013;115:943-9.

Rajkumar D, Palanivelu K. Electrochemical treatment of industrial wastewater. J Hazard Mater. 2004;113:123-9.

Stuer-Lauridsen F, Birkved M, Hansen L, Lützhøft H-CH, Halling-Sørensen B. Environmental risk assessment of human pharmaceuticals in Denmark after normal therapeutic use. Chemosphere. 2000:40:783-93.

Thiele S. Adsorption of the antibiotic pharmaceutical compound sulfapyridine by a long-term differently fertilized loess Chernozem. J Soil Sci Plant Nutr. 2000;163:589-94.

Tiravanti G, Petruzzelli D, Passino R. Pretreatment of tannery wastewaters by an ion exchange process for $\mathrm{Cr}$ (III) removal and recovery. Wat Sci Tech. 1997;36:197-207.

United States Pharmacopeia (2009). The National Formulary USP USPCI.

Vasiliu S, Bunia I, Racovita S, Neagu V. Adsorption of cefotaxime sodium salt on polymer coated ion exchange resin microparticles: kinetics, equilibrium and thermodynamic studies. Carbohydr Polym. 2011;85:376-87.

Wang J, Mao D, Mu Q, Luo Y. Fate and proliferation of typical antibiotic resistance genes in five full-scale pharmaceutical wastewater treatment plants. Sci Total Environ. 2015;526:366-73.

Wang P, Yuan T, Hu J, Tan Y. Determination of cephalosporin antibiotics in wate samples by optimised solid phase extraction and high performance liquid chromatography with ultraviolet detector. Int J Environ Anal Chem. 2011;91:1267-81.

Wang S, Peng Y. Natural zeolites as effective adsorbents in water and wastewater treatment. Chem Eng J. 2010;156:11-24.

Yu X, Tang X, Zuo J, Zhang M, Chen L, Li Z. Distribution and persistence of cephalosporins in cephalosporin producing wastewater using SPE and UPLC-MS/MS method. Sci Total Environ. 2016;569:23-30.

Zuccato E, Calamari D, Natangelo M, Fanelli R. Presence of therapeutic drugs in the environment. Lancet. 2000;355:1789-90.

\section{Submit your manuscript to a SpringerOpen ${ }^{\circ}$ journal and benefit from:}

- Convenient online submission

- Rigorous peer review

- Open access: articles freely available online

- High visibility within the field

- Retaining the copyright to your article

Submit your next manuscript at $\boldsymbol{\nabla}$ springeropen.com 